\title{
Accepted Publication
}

\section{The Crooked Tree: An Essay and Sculpture}

Hettiarachchige Diluksha Prasad Jayawardana

DOI: $\quad 10.15404 / \mathrm{msrj} / 08.2021 .212$

Reference: MSRJ

To appear in: $\quad$ Medical Student Research Journal

Received Date: 3 September 2020

Revised Date: 23 December 2020

Accepted Date: 15 August 2021

This is a PDF file of an unedited manuscript that has been accepted for publication. As a service to our customers we are providing this early version of the manuscript. The manuscript will undergo copyediting, typesetting, and review of the resulting proof before it is published in its final form. Please note that during the production process errors may be discovered which could affect the content, and all legal disclaimers that apply to the journal pertain. 


\title{
The Crooked Tree: An Essay and Sculpture
}

\author{
Hettiarachchige Diluksha Prasad Jayawardana
}

Faculty of Medicine, University of Colombo, 25 Kynsey Road, Colombo 08, Sri Lanka. Medical student author

\section{Corresponding author:}

Hettiarachchige Diluksha Prasad Jayawardana

dilukshaprasad@gmail.com 


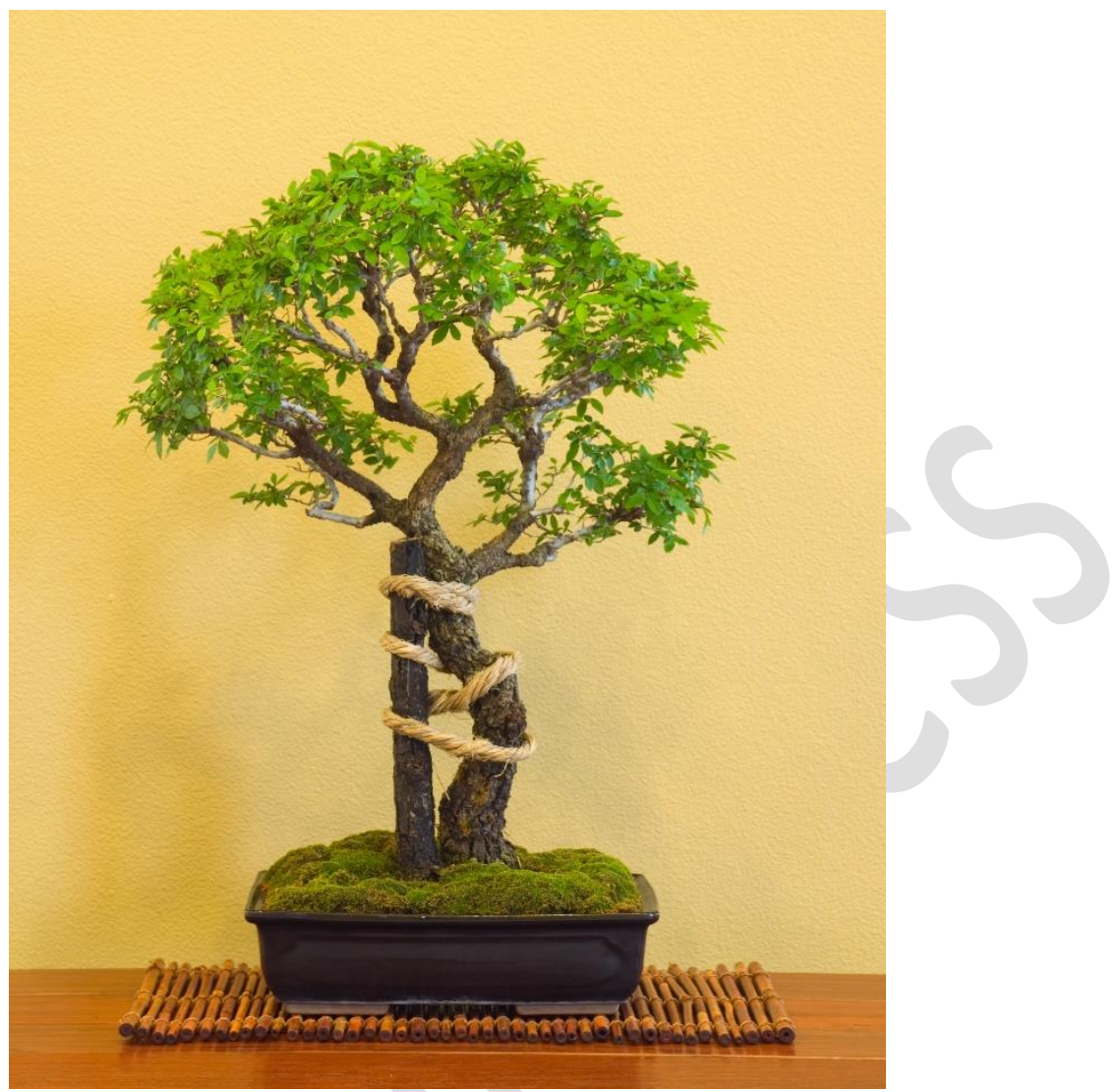

The Crooked Tree. ${ }^{1}$

Some months ago, I participated in an orthopedic surgery workshop as a medical student delegate. There was an eye-catching centerpiece in one stall that serves as the logo for many orthopedic organizations. It was a small tree strapped to a stake by a rope. This tree was an illustration of the idea behind the prevention and correction of bone deformities in children of the $17^{\text {th }}$ century. ${ }^{2}$ Each part of this tree served to represent the relationship between orthopedic surgery and nature.

Bent trunk with a rope around it: The trunk of this crooked tree was strapped to a stake. Simply, it is to make straight the trunk of the young tree. The same strategy is applied in clinical practice to treat fractures, crooked spines, and straighten bowed legs of children. To become an orthopedic surgeon; a physician has to master general orthopedics for five years with additional one year training in a chosen orthopedic subspecialty. Therefore, the strapped trunk illustrates an orthopedic trainee mastering general orthopedic skills with the guidance of senior clinicians and curving his career to deliver better orthopedic care. Perhaps the bent trunk rather than the straight trunk denotes the gratefulness, respectfulness, as well as humbleness of the trainee to his/her teachers, peers, and of course to the patients. 
Branches: The field of orthopedics has two different components. They are orthopedic subspecialties and various scopes of treatment. The subspecialties are Hand and Upper Extremity, Arthroplasty, Pediatric Orthopedics, Foot and Ankle Surgery, Spine Surgery, Orthopedic Oncology, Sports Medicine, and Orthopedic Trauma. ${ }^{3}$ The scopes of treatment include management of fractures and dislocations, torn ligaments, sprains, tendon injuries, pulled muscles, bursitis, ruptured disks, sciatica, low back pain, scoliosis, knock knees, bow legs, bunions, hammertoes, arthritis, osteoporosis, bone tumors, muscular dystrophy, cerebral palsy, club foot, unequal leg length, abnormalities of the fingers and toes, and growth abnormalities of bones, etc. ${ }^{4}$ Therefore, branches of the crooked tree adequately depict the compilation of pathologies encompassed by orthopedic surgery. On the contrary, the branches could also highlight the subspecialty training of an orthopedic resident in a chosen field after completing the general orthopedic training.

Buds and Leaves: Orthopedic surgery is an advancing medical field. Day-by-day, discoveries at the molecular and population-level come to light for improvement of patient care. The field has evolved in understanding and technology since Nicholas Andry's first description. For example, the evolution of arthroscopy, a method of visualizing the interior joint, has opened a new era of therapy. It is consistent with the budding and growing of young leaves of the tree. Likewise, an orthopedic trainee gains new clinical experiences and knowledge every day throughout his career similar to the tree budding and leafing daily.

Roots: The roots of this tree depict the basics of modern orthopedics and its principles. The modern technology of orthopedics has been evolved on the discoveries from the forefathers of orthopedics over decades. Therefore, orthopedists still look at roots when faced with patient care decisions. Finally, strong roots keep the tree steady, just as our skeleton provides structure to the flesh.

It is my sincerest hope that I have successfully captured the meaning of this tree famous to orthopedists worldwide. From the roots to the new leaves, there are many translations to the field of orthopedic surgery hidden in this small crooked tree that can serve as a discussion between those that wish to ponder the meaning. 
References

1.Wongworawat MD. The Living Orthopaedic Tree. 2007; Accessed Aug 31, 2020. Image reproduced with permission from Wongworawat, MD.

2. Ponseti IV. History of Orthopaedic Surgery. Iowa Orthop J. 1991;11:59-64. Accessed Aug 31, 2020.

3. American College of Surgeons. Orthopedic surgery. 2020; Accessed Sept 03, 2020.

4. Orthopedic Doctors. Physical Therapy Clinics in Council, Idaho. 2020; Accessed Sept 03, 2020 . 